\title{
Increased Predictability of Spring Precipitation over Central East China around the Late 1970s
}

\author{
MENGQI ZHANG \\ Nansen-Zhu International Research Center, Institute of Atmospheric Physics, Chinese Academy of Sciences, and \\ University of Chinese Academy of Sciences, Beijing, China \\ JIANQI SUN \\ Nansen-Zhu International Research Center, Institute of Atmospheric Physics, Chinese Academy of Sciences, Beijing, and \\ Joint Laboratory for Climate and Environmental Change at Chengdu University of Information Technology, Chengdu, and \\ University of Chinese Academy of Sciences, Beijing, China
}

(Manuscript received 21 July 2018, in final form 14 March 2019)

\begin{abstract}
The predictability of spring (March-May) precipitation over East China is investigated, based on the February-start hindcasts of eight coupled models from DEMETER and ENSEMBLES during 1960-2001. Five out of the eight models exhibit significantly increased predictability of central East China spring precipitation (CECSP) after the late 1970s. The mechanism analysis indicates that CECSP variability is closely related to a meridional dipole vorticity pattern at $200 \mathrm{hPa}$ and southerly wind at $850 \mathrm{hPa}$ over East Asia, whose prediction skill increased significantly around the late 1970s, consistent with the changes in CECSP predictability. Observational analysis indicates that the sea surface temperature (SST) over the tropical Pacific and Indian Oceans experienced a notable decadal change around the late 1970s. After the decadal change, the tropical SST has an enhanced impact on the CECSP-related East Asian dipole vorticity pattern at the upper level and on the western North Pacific anticyclone at the lower level. The five models can adequately reproduce the observed enhanced connection between the tropical SST and East Asian atmospheric circulation after the late 1970s, consequently showing higher predictability of East Asian atmospheric circulation and CECSP. However, the other three models cannot reproduce the relationship between the tropical SST and East Asian atmospheric circulation; therefore, CECSP predictability in these models remains low during the entire period. The increased predictability is valuable for current dynamical seasonal prediction for central East China.
\end{abstract}

\section{Introduction}

Spring precipitation has a large interannual variation over East China, although the total amount is not as large as that in the summer. Anomalous precipitationrelated severe droughts and floods directly influence spring plowing and social activity, causing large economic losses (e.g., Rong et al. 2008; Sun and Yang 2012; Jin et al. 2013). For example, a great flood over the Huang-huai area and South China in the spring of 2009 left more than 10 million people afflicted and caused a direct economic loss of 3 billion yuan; meanwhile, a record-breaking drought hit Heilongjiang Province, causing damage to half of the arable land (Gao 2009).

Corresponding author: Jianqi Sun, sunjq@mail.iap.ac.cn
Therefore, a better understanding of the variability in East China spring precipitation and further improving its prediction skill are of great significance.

Previous studies have shown that the variability in East China spring precipitation is closely related to the atmospheric circulations over middle to high latitudes and tropical convection anomalies, such as the North Atlantic Oscillation (NAO; Xin et al. 2006; Shao and Zhang 2012; Zhou 2013), the Asian-Pacific Oscillation (APO; Zhou and Zhao 2010), the East Asian trough (Lu 2001; Zuo and Zhang 2012), the deep convection over the South China Sea and Philippine Sea (Z. N. Li et al. 2016), the western North Pacific subtropical high (Han et al. 2006), the Southern Hemisphere annular mode (Zheng et al. 2015), and the polar vortex and East Asian jet stream (Wang et al. 2002; Zhang et al. 2009). Such 
influencing factors are helpful in understanding the variability in East China spring precipitation.

For the prediction of East China spring precipitation, slow-varying physical progress is especially important. In particular, tropical sea surface temperature (SST) anomalies are generally recognized as the primary sources of seasonal atmospheric variability and predictability worldwide (e.g., Chowdary et al. 2011; Wang et al. 2009; Lee et al. 2013). Some previous studies have pointed out that tropical SSTs over the Indian Ocean and eastern Pacific Ocean played critical roles in the variability in East China spring precipitation (e.g., Feng and Li 2011; Zuo and Zhang 2012). Additionally, the tropical SST experienced an interdecadal change toward a warmer state after the late 1970s (Nitta and Yamada 1989; Wallace et al. 1998; Lau and Weng 1999; Terray and Dominiak 2005). A recent study documented that, along with the decadal change in the tropical SST, the relationship between the East China spring precipitation and tropical SST was enhanced after the late 1970s (Zhang and Sun 2018), which raises the question of whether the seasonal predictability for East China spring precipitation changed around this time. Motivated by this question, we performed this study based on multimodel hindcasts during the period of 1960-2001.

The paper is organized as follows: Descriptions of the models and datasets are given in section 2, and interdecadal changes in the predictability of East China spring precipitation are explored in section 3, which is followed by the interpretation of possible mechanisms in section 4 . A discussion and conclusions are presented in section 5.

\section{Models and datasets}

The retrospective forecast dataset used in this study is derived from eight global ocean-atmosphere coupled general circulation models (CGMs) that come from two European Union (EU)-funded seasonal prediction projects: the development of a European multimodel ensemble system for seasonal-to-interannual prediction (DEMETER; Palmer et al. 2004) and the development of an ensemble prediction system for climate change (ENSEMBLES; Weisheimer et al. 2009). The three coupled models, namely, the Centre National de Recherches Météorologiques (CNRM), the Met Office (UKMO), and the European Centre for Medium-Range Weather Forecasts (ECMWF), are from the DEMETER project. The five coupled models, namely, the UKMO, Météo-France (MF), ECMWF, the Leibniz Institute of Marine Sciences at Kiel University (IFM-GEOMAR), and the Euro-Mediterranean Center for Climate Change (CMCC-INGV), are from the ENSEMBLES project. Hindcasts in DEMETER (ENSEMBLES) are integrated for 6 (7) months, and each model was run with an ensemble of nine initial conditions. The common hindcast period of all eight models covers 42 years from 1960 to 2001. In the present study, we focus on 1-month-lead seasonal forecasts with the initial conditions on 1 February and target the March-May (MAM) seasonal forecast. More details on the initial conditions of the DEMETER and ENSEMBLES multimodel projects can be found in Palmer et al. (2004) and Doblas-Reyes et al. (2009). The multimodel ensemble (MME) is constructed by applying equal weights to the selected models. In this study, the linear trends of the data were first removed before analysis.

The observation data used for model verification are as follows: 1) monthly mean reanalysis data from the National Centers for Environmental Prediction and National Center for Atmospheric Research (NCEPNCAR Reanalysis 1; Kalnay et al. 1996); 2) the National Oceanic and Atmospheric Administration (NOAA) extended reconstructed SST, version 4 (ERSST.v4), dataset (Huang et al. 2015); and 3) monthly precipitation data over 160 stations in China provided by the China Meteorological Administration.

\section{Interdecadal change in the predictability of central East China spring precipitation}

In this study, central East China spring precipitation (CECSP; $30^{\circ}-45^{\circ} \mathrm{N}, 102.5^{\circ}-120^{\circ} \mathrm{E}$ ) is mainly focused since the dominant mode of East China spring precipitation (represented by the precipitation anomaly percentage) is basically consistent and shows the largest variability over the region (Wu and Mao 2018; Zhang and Sun 2018). A central East China precipitation index (CECPI) is defined as the area-averaged precipitation anomaly percentage over the region of $30^{\circ}-45^{\circ} \mathrm{N}, 102.5^{\circ}-$ $120^{\circ} \mathrm{E}$. The precipitation anomaly percentage is calculated as the percentage of precipitation anomalies relative to the climatological mean. The CECPI is highly correlated with the time series of the leading empirical orthogonal function (EOF1) of East China spring precipitation (east of $100^{\circ} \mathrm{E}$ ), with a correlation coefficient of 0.99 during 1960-2001, further indicating that the CECSP variability can well represent the major feature of the East China spring precipitation variability.

The tropical SST experienced an interdecadal shift in 1976/77 (e.g., Nitta and Yamada 1989; Trenberth 1990; Graham 1995), and the related atmospheric teleconnection has undergone significant changes concurrent with the tropical SST shift (e.g., Wu and Wang 2002; Annamalai et al. 2005; Wang et al. 2008; Rajeevan et al. 2012; Li et al. 2015; Pradhan et al. 2017). The work by Zhang and Sun (2018) demonstrated that the relationship between CECSP and tropical SST was enhanced after the late 1970s 
TABLE 1. Correlation coefficients of the CECPI between the observations and model predictions during 1960-76 and 1981-2001. The MME5 is the ensemble mean of five models in group 1. Single, double, and triple asterisks indicate that the correlation coefficients are statistically significant at the $90 \%, 95 \%$, and $99 \%$ confidence levels, respectively.

\begin{tabular}{lcc}
\hline & $1960-76$ & $1981-2001$ \\
\hline ENSEMBLES & & \\
ECMWF & 0.05 & 0.27 \\
IFM-GEOMAR & $-0.48^{* *}$ & $0.44^{* *}$ \\
MF & -0.17 & -0.07 \\
UKMO & 0.23 & $0.39^{*}$ \\
CMCC-INGV & -0.35 & -0.20 \\
DEMETER & & \\
CNRM & -0.36 & $0.56^{* * *}$ \\
UKMO & 0.10 & $0.48^{* *}$ \\
ECMWF & 0.01 & $0.40^{*}$ \\
MME5 & -0.30 & $0.77^{* * *}$ \\
\hline
\end{tabular}

due to the interdecadal warming of tropical SST. Therefore, the period in the present study is divided into two subperiods of 1960-76 and 1981-2001. Table 1 evaluates the predication skill of CECSP in eight models by the correlations of the CECPI between observation and model predictions over the two periods of 1960-76 and 1981-2001. During 1960-76, low prediction skill is found in each model; in particular, there are four models showing negative correlations. In contrast, all eight models exhibit increased skill during 1981-2001. In particular, there are five models that show significant prediction skill after the late 1970s. Based on Table 1, the eight models are divided into two groups. The five models with significant correlations during 19812001 are assigned to group 1, and the remaining three models with weak correlations are assigned to group 2 .

Considering the poor prediction skill of group 2, these three models are discussed in section 5. Thus, the MME is first made on the basis of the five coupled models of group 1 (hereafter MME5), which have high prediction skill for CECSP after the late 1970s. The correlation coefficient of CECPI between the observation and MME5 predication is 0.77 during 1981-2001, which is significant at the $99 \%$ confidence level. Notably, the MME5 exhibits superior prediction skill compared with any of the individual models, consistent with previous studies (e.g., DoblasReyes et al. 2005; Hagedorn et al. 2005; Wang et al. 2009; Chowdary et al. 2010). The error cancellation and nonlinearity of the diagnostics are the main reasons that account for the MME superiority (Hagedorn et al. 2005), which could lead to a more consistency and reliable prediction than that of any single model (e.g., Doblas-Reyes et al. 2000; Hagedorn et al. 2005).

Figure 1 illustrates the 21-yr running correlations between the observed and predicted CECPI during 1960 2001. Increased predictability of the CECPI is found for

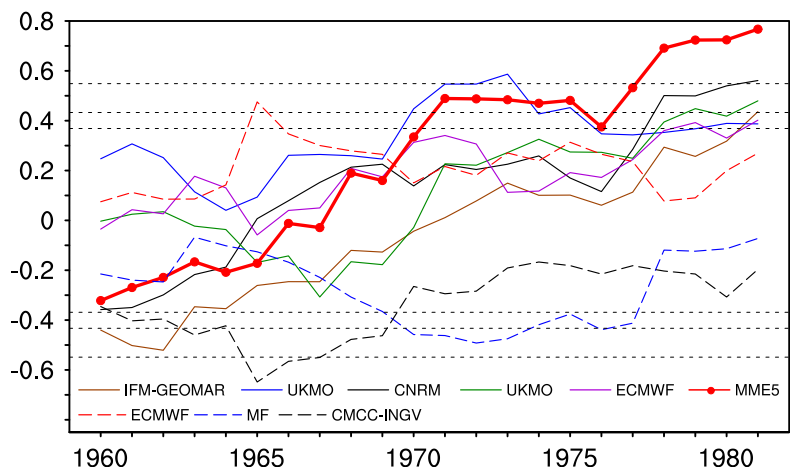

FIG. 1. The 21-yr running correlations of the CECPI between the observation and model predictions during the period of 1960-2001. The solid (dashed) lines represent the predictions of five (three) individual models in group 1 (group 2). The red line with solid circles represents the result of the MME5 prediction. The $90 \%$, $95 \%$, and $99 \%$ confidence levels are shown by the horizontal dashed lines.

the five individual models in group 1 and MME5, with relatively low skill before the late 1970s and significantly high skill after the late 1970s. The time series of MME5 display an upward trend during the past few decades and exceed the $99 \%$ confidence level after the late 1970s. Before the late 1970s, the correlation of the CECPI between the observation and MME5 prediction is only -0.30 ; however, it increases to 0.77 after the late 1970s (Table 1). The dispersion between individual models in group 1 decreases with time, indicating increased fidelity of each model in group 1 . In contrast, the prediction skill of the three models in group 2 is low or negative during the whole period, consistent with Table 1.

Figure 2 depicts the temporal correlation coefficient (TCC) of spring precipitation between the observation and MME5 prediction at each grid during 1960-76 and 1981-2001. Before the late 1970s, negative correlations are found over most areas of central East China; therefore, MME5 has low skill in capturing precipitation anomalies over central East China during this period. In contrast, after the late 1970 s, significantly positive correlations dominate central East China, which is consistent with the results in Table 1 and Fig. 1. The TCC pattern in the latter period shows spatial similarity to that of the EOF1 of East China spring precipitation (Zhang and Sun 2018). Figure 2c displays the differences in prediction skill between the two periods. Considerable improvements of prediction are found over central East China. The above results suggest that the predictability of spring precipitation increased significantly over central East China after the late 1970s.

It is also noted that the predictability of spring precipitation over northeast and southeast China decreased 
(a) $1960-1976$ TCC $\quad 90 \%$

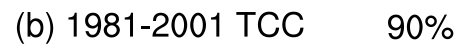

(c) $b-a$
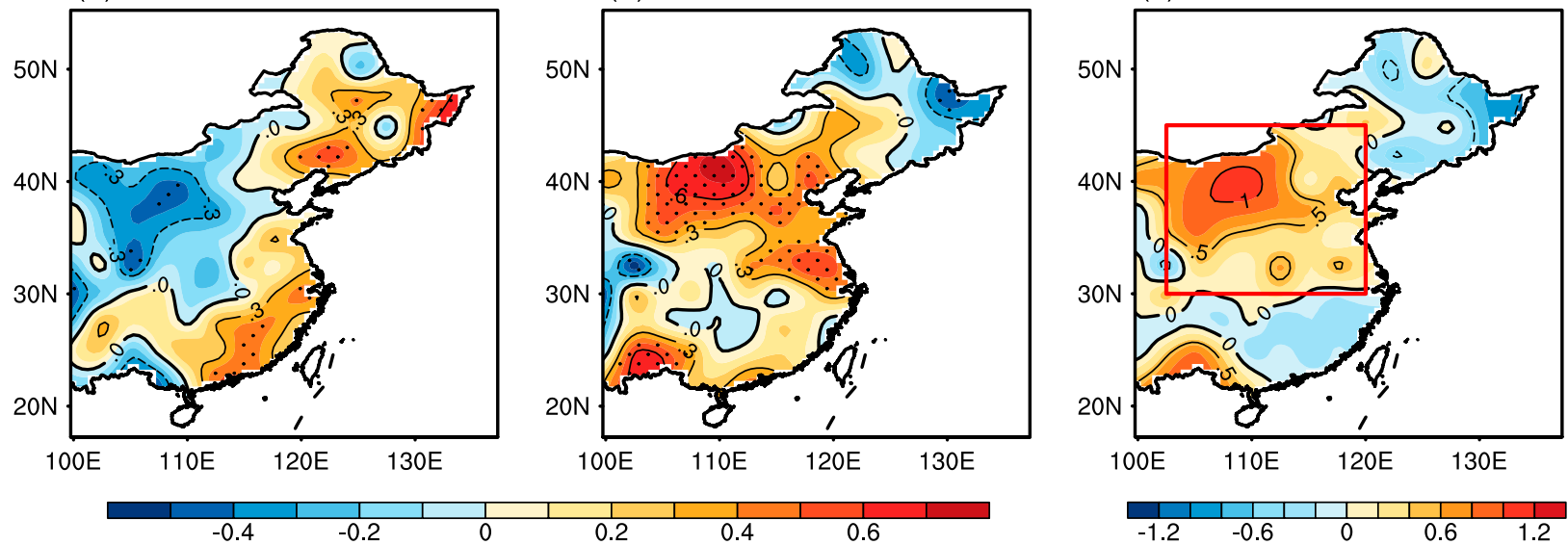

FIG. 2. Temporal correlation coefficients (TCCs) of spring precipitation between the observation and MME5 prediction during (a) 1960-76 and (b) 1981-2001. (c) The difference between (b) and (a). Areas that are statistically significant at the 90\% confidence level are stippled. The red rectangle in (c) indicates the domain used to define the CECPI.

over the period after the late 1970s compared to before (Fig. 2). Preliminary analyses indicate that the models could not simulate the observed interdecadal change in the atmospheric circulations associated with these two regions' spring precipitation, which could result in the decreased predictability of spring precipitation over the two regions. The detailed possible mechanism for the decrease in precipitation predictability over northeast and southeast China will be explored in another study.

\section{Possible mechanism for the interdecadal change in the CECSP predictability}

The previous section identified the improved predictability of spring precipitation over central East China after the late 1970s. Subsequently, efforts are made in this section to address the possible mechanisms that are responsible for the increased prediction skill of the coupled modes during the latter period.

\section{a. Interdecadal change in the seasonal prediction skill of CECSP-related atmospheric circulation}

Figure 3 depicts the CECPI-related anomalous vorticity at $200 \mathrm{hPa}$ and the corresponding wave activity fluxes (WAFs) in the observation and MME5 prediction during the period of 1981-2001. As shown in Fig. 3a, the observed upper-level vorticity anomaly is characterized as a meridional dipole pattern between the subtropics $\left(20^{\circ}-30^{\circ} \mathrm{N}\right)$ and midlatitudes $\left(30^{\circ}-45^{\circ} \mathrm{N}\right)$ over the East Asia-northwestern Pacific region. This dipole vorticity pattern is similar to the so-called Pacific-Japan (PJ) pattern (Nitta 1987, 1989; Nitta and Hu 1996; Wakabayashi and Kawamura 2004), which provides a crucial link between the tropics and midlatitudes. Further, a PJ index is defined as the time series of the leading mode of the $850-\mathrm{hPa}$ vorticity over $0^{\circ}-60^{\circ} \mathrm{N}, 100^{\circ}-160^{\circ} \mathrm{E}$ (Kosaka et al. 2013; Srinivas et al. 2018). Based on Fig. 3, a vorticity index (VORI) is defined as the difference in the normalized time series of area-averaged vorticity at $200 \mathrm{hPa}$ between the regions of $17.5^{\circ}-30^{\circ} \mathrm{N}, 80^{\circ}-160^{\circ} \mathrm{E}$ and $32.5^{\circ}-45^{\circ} \mathrm{N}, 95^{\circ}-$ $152.5^{\circ} \mathrm{E}$ (red rectangles in Fig. $3 \mathrm{~b}$ ). The VORI is significantly correlated with the PJ index, with a correlation coefficient of 0.59 during 1981-2001. Therefore, the dipole vorticity pattern could be considered as the upper-level
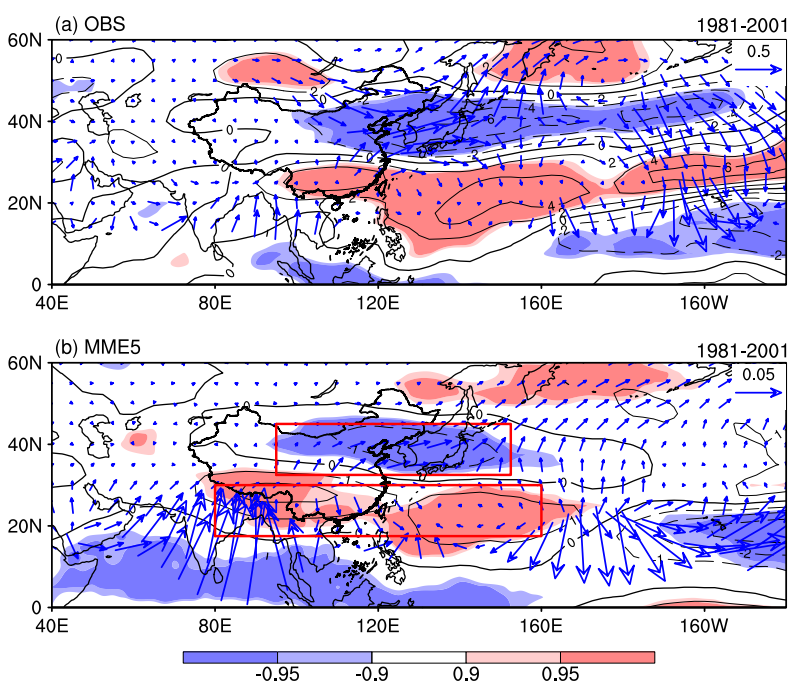

FIG. 3. Regressions of the 200-hPa vorticity (contours; $10^{-6} \mathrm{~s}^{-1}$ ) against the normalized CECPI during 1981-2001 and the related WAFs (vectors; $\mathrm{m}^{2} \mathrm{~s}^{-2}$ ) in the (a) observation and (b) MME5 prediction. Light (dark) shading indicates areas that are statistically significant at the $90 \%(95 \%)$ confidence level. The red rectangles in (b) indicate the domains used to define the VORI. 
TABLE 2. Correlation coefficients of the VORI and V850 index with the CECPI in the observation and model predictions (five models in group 1 and MME5) during 1960-76 and 1981-2001. Single, double, and triple asterisks indicate that the correlation coefficients are statistically significant at the $90 \%, 95 \%$ and $99 \%$ confidence levels, respectively.

\begin{tabular}{|c|c|c|c|c|}
\hline & \multicolumn{2}{|c|}{ VORI } & \multicolumn{2}{|c|}{ V850 index } \\
\hline & $1960-76$ & 1981-2001 & $1960-76$ & 1981-2001 \\
\hline \multicolumn{5}{|l|}{ ENSEMBLES } \\
\hline IFM-GEOMAR & $0.74 * * *$ & $0.57 * * *$ & $0.82 * * *$ & $0.84 * * *$ \\
\hline UKMO & $0.65 * * *$ & $0.37 *$ & $0.62 * * *$ & $0.57 * * *$ \\
\hline \multicolumn{5}{|l|}{ DEMETER } \\
\hline CNRM & $0.73 * * *$ & $0.59 * * *$ & $0.84 * * *$ & $0.59 * * *$ \\
\hline UKMO & $0.52 * *$ & $0.50 * *$ & $0.70 * * *$ & $0.71 * * *$ \\
\hline ECMWF & 0.24 & $0.66^{* * *}$ & $0.60 * *$ & $0.78 * * *$ \\
\hline MME5 & 0.40 & $0.65 * * *$ & $0.59 * *$ & $0.76 * * *$ \\
\hline OBS & $0.59 * *$ & $0.76 * * *$ & $0.60 * *$ & $0.78 * * *$ \\
\hline
\end{tabular}

manifestation of the so-called PJ pattern. In the MME5 prediction, the CECPI-related vorticity anomalies at the upper level also feature a dipole pattern in the south-north direction, similar to that in the observation, although the predicted intensity and distribution have visible differences from the observation (Fig. 3b). Further, WAFs are used to examine the propagations of wave train energy. In the observation, there are two Rossby waves that contribute to the negative vorticity anomalies over midlatitude East Asia (centered over the Japan Sea). One is a zonal wave train dispersing southeastward from the MongoliaBaikal Lake region to midlatitude East Asia; the other is a meridional wave train originating from the north Indian Ocean and propagating northeastward to midlatitude East Asia. The two Rossby waves eventually converge over midlatitude East Asia and then propagate farther northward. The observed result suggests that the CECSP is modulated by both the tropical forcing and midlatitude processes, consistent with previous studies (e.g., Han et al. 2006). The MME5 prediction exhibits considerable capability in capturing the Rossby wave migrating in the meridional direction, with a strong wave energy propagating from the north Indian Ocean to South China and further dispersing to midlatitude East Asia. In contrast, the observed zonal wave train from the Mongolia-Baikal Lake region is not reproduced by the MME5 prediction. The wave activity from the midlatitudes might be related to snow cover anomalies over the Mongolia-Baikal Lake region. The deficiency of the MME5 prediction might reflect the deficiency of the numerical models in capturing the land forcing-atmospheric response process over this region. Therefore, the predictability of the CECSP in dynamic models should rely on tropical forcings.

Since the CECSP is closely related to the atmospheric dipole pattern at $200 \mathrm{hPa}$ over East Asia, the increased

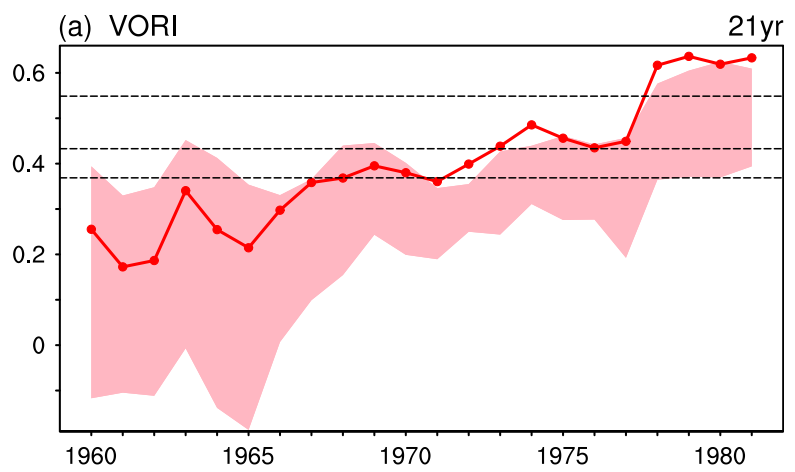

(b) V850 index

$21 \mathrm{yr}$

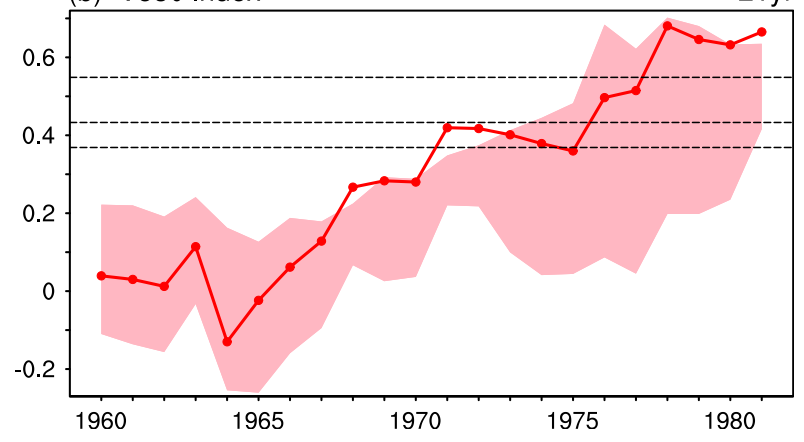

FIG. 4. The 21-yr running correlations between the observed and predicted (a) VORI and (b) V850 index during the period of 19602001. The lines (shading) represent the MME5 predictions (range of predictions of five individual models in group 1). The horizontal dashed lines indicate the $90 \%, 95 \%$, and $99 \%$ confidence levels.

predictability of CECSP could be associated with the increased prediction skill of the atmospheric dipole pattern. To confirm the aforementioned deduction, the correlation coefficient between CECPI and VORI is examined in model predictions and observations during both periods (Table 2). The CECPI is significantly correlated with VORI in the five models of group 1 and in MME5, as well as in the observation during 1981-2001. Thus, it is reasonable to use the VORI to investigate the cause of increased predictability of CECPI in the models of group 1.

Figure 4a evaluates the predictability of the CECSPrelated atmospheric dipole pattern by calculating the 21-yr running correlations between the observed and predicted VORI during the period of 1960-2001. The predictability of VORI exhibits an upward trend for each model and the MME5. The time series of MME5 shows an increased trend and exceeds the 99\% confidence level after the late 1970s. The improvements in predictability are also confirmed by the corresponding correlation coefficients (Table 3). From 1960-76 to 1981-2001, all models exhibit increased prediction skill. The prediction correlations of VORI are relatively low and insignificant during 1960-76, whereas they are significantly higher in all of the individual models and their MME during 1981-2001. Further 
TABLE 3. Correlation coefficients between the observed and predicted VORI and V850 index during 1960-76 and 1981-2001 for the five models in group 1 and their MME. Single, double, and triple asterisks indicate that the correlation coefficients are statistically significant at the $90 \%, 95 \%$, and $99 \%$ confidence levels, respectively.

\begin{tabular}{lrllll}
\hline \hline & \multicolumn{2}{c}{ VORI } & & \multicolumn{2}{c}{ V850 index } \\
\cline { 2 - 3 } \cline { 5 - 6 } & $1960-76$ & $1981-2001$ & & $1960-76$ & $1981-2001$ \\
\hline ENSEMBLES & & & & & \\
$\quad$ IFM-GEOMAR & 0.12 & $0.44^{* *}$ & & -0.13 & $0.42^{*}$ \\
$\quad$ UKMO & -0.12 & $0.57^{* * *}$ & & 0.08 & $0.45^{* *}$ \\
DEMETER & & & & & \\
$\quad$ CNRM & 0.11 & $0.61^{* * *}$ & & -0.03 & $0.44^{* *}$ \\
UKMO & 0.38 & $0.39^{*}$ & & 0.30 & $0.45^{* *}$ \\
ECMWF & 0.23 & $0.57^{* * *}$ & & 0.01 & $0.63^{* * *}$ \\
MME5 & 0.21 & $0.63^{* * *}$ & & 0.04 & $0.67 * * *$ \\
\hline
\end{tabular}

analyses suggest that the two centers of the upper-level dipole vorticity pattern exhibit significantly increased predictability (figure not shown). The correlation coefficient of the northern center between the observation and MME5 prediction increased from 0.09 (1960-76) to 0.43 (1981-2001), and that of the southern center increased from 0.43 (1960-76) to 0.73 (1981-2001). Therefore, the significantly increased predictability of the upper-level atmospheric dipole circulation over East Asia favors the high predictability of central East China spring precipitation after the late 1970s.

In addition to the upper-level circulation, the lowerlevel circulation anomalies are examined by regressing the $850-\mathrm{hPa}$ winds and geopotential heights against the CECPI in the observation and MME5 for 1981-2001 (Fig. 5). In the observation, corresponding to abovenormal CECSP, there is a meridional dipole structure of anomalous geopotential heights in the western North Pacific, with cyclonic anomalies over the Bering Sea region and anticyclonic anomalies over the midlatitude western North Pacific and East Asia. This dipole pattern resembles the west Pacific pattern (WP pattern; Wallace and Gutzler 1981; Barnston and Livezey 1987). The anomalous southerly along the west flank of the anticyclonic anomaly brings warm and wet air to central East China, favoring more precipitation over the region. The MME5 prediction could generally simulate the observed lower-level circulations associated with CECPI, with meridional dipole geopotential height anomalies over the western North Pacific and East Asia, although the centers are southward shifted compared to the observation. The observed southerly over East China is also captured by the MME5.

Furthermore, the predictability of the CECSP-related lower-level southerly is examined using a V850 index (defined as area-averaged meridional wind at $850 \mathrm{hPa}$ (a) OBS

$1981-2001$

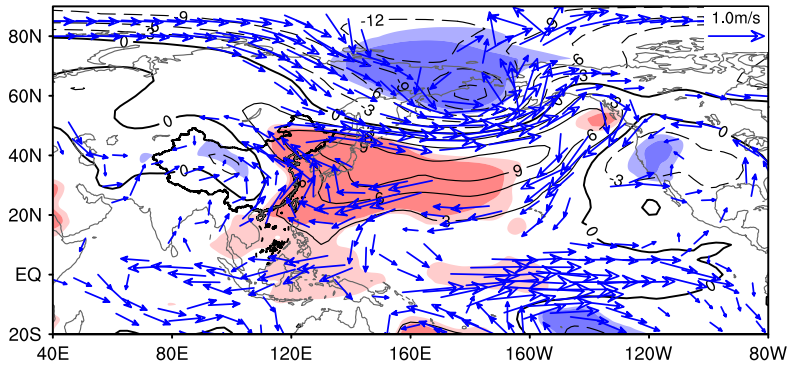

(b) MME5

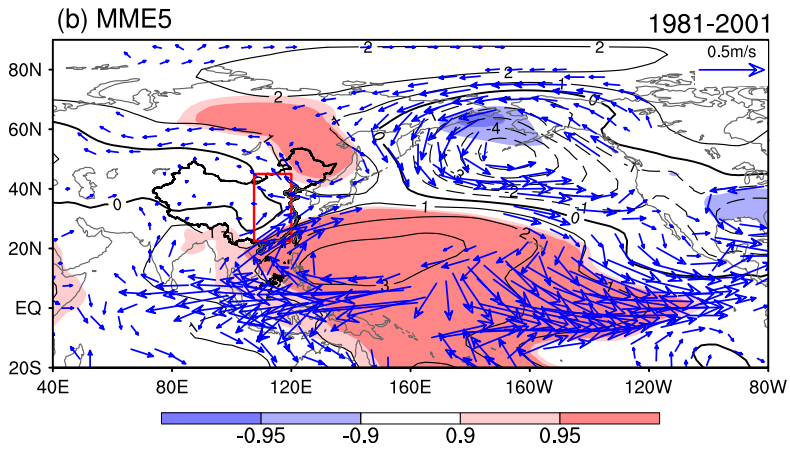

FIG. 5. Regressions of the $850-\mathrm{hPa}$ geopotential heights (contours; gpm) and winds (vectors; $\mathrm{m} \mathrm{s}^{-1}$ ) against the normalized CECPI during 1981-2001 in the (a) observation and (b) MME5 prediction. Light (dark) shading indicates areas significant at the $90 \%(95 \%)$ confidence level. Only wind vectors that are statistically significant at the $90 \%$ confidence level are shown. The red rectangle in (b) indicates the domains used to define the V850 index.

over the region $22.5^{\circ}-45^{\circ} \mathrm{N}, 107.5^{\circ}-120^{\circ} \mathrm{E}$; red rectangle in Fig. 5b). The CECPI is significantly correlated with the V850 index in all the individual models and their ensembles, as well as in the observation during both periods (Table 2). The running correlations between the observed and predicted V850 index with a 21-yr window are illustrated in Fig. 4b. All five individual models of group 1 and MME5 exhibit increased prediction skill for the V850 index during the past few decades. The running correlations of MME5 exhibit an increasing trend, exceeding the $99 \%$ confidence level after the late 1970s. Table 3 confirms the increased prediction skill of the V850 index with low correlation coefficients over the former period and high correlation coefficients over the latter period. Thus, the increased predictability of CECSP-related meridional wind in the lower troposphere also favors high predictability of CECSP after the late 1970s.

\section{b. Possible mechanisms for interdecadal change in the predictability of CECSP-related atmospheric circulation}

The aforementioned results suggest that the increased prediction skill of central East China spring precipitation is associated with the increased fidelity of 

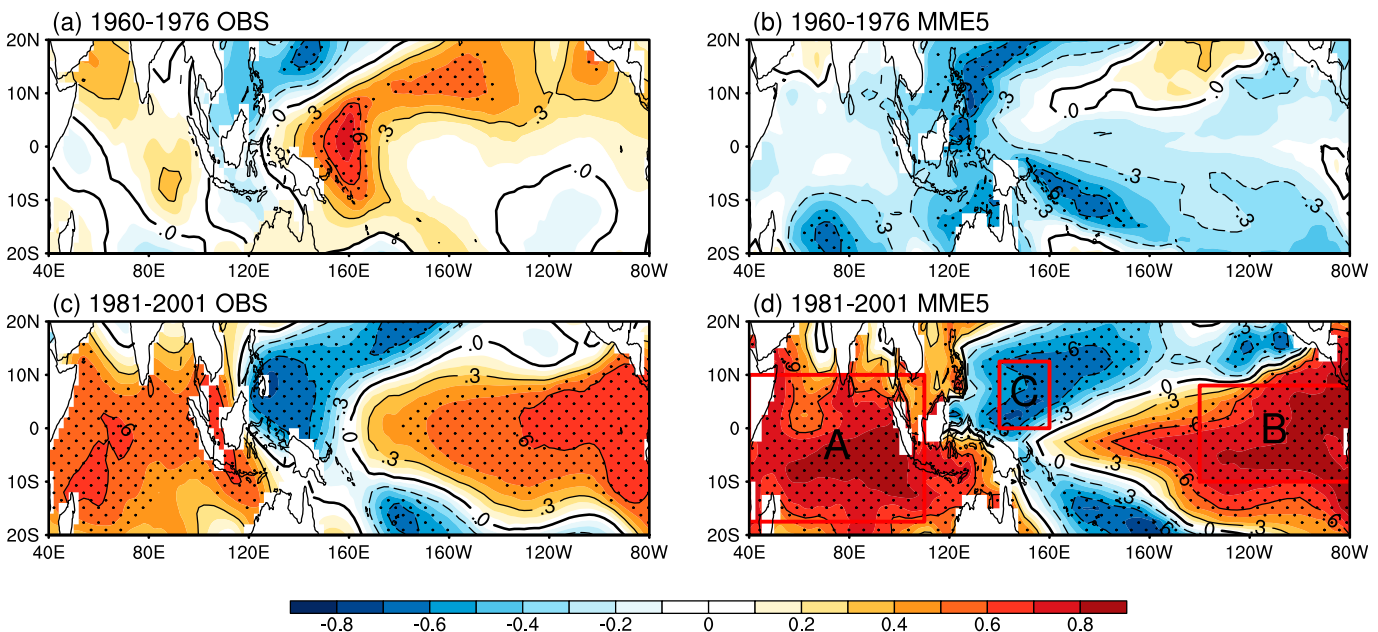

FIG. 6. Correlations of tropical SST associated with the VORI during (a),(b) 1960-76 and (c),(d) 1981-2001 in the (left) observations and (right) MME5 predictions. Areas that are statistically significant at the $95 \%$ confidence level are stippled. The red rectangles in (d) indicate the domains used to define the tropical SST index.

dynamic models in forecasting the upper-level meridional dipole vorticity pattern and lower-level meridional winds over East Asia. This section strives to investigate the possible mechanisms for the significant improvement of seasonal forecast skill in the CECSP-related circulations in the upper and lower troposphere. In dynamical prediction, tropical SST anomalies are generally considered to be the major sources of seasonal predictability. Therefore, the tropical SST anomalies associated with the VORI and V850 index are diagnosed in the observation and MME5 predictions, respectively, during the periods of 1960-76 and 1981-2001.

As shown in Figs. 6 and 7, in the observations, there are enhanced relationships of the tropical SST with the VORI and V850 index after the late 1970s. During
1960-76, few tropical regions are significantly correlated with the VORI and V850 index (Figs. 6a and 7a). In contrast, during 1981-2001, there are significant zonal positive-negative-positive SST anomalies over the tropical ocean, imitating an ENSO-like SST structure (Figs. $6 \mathrm{c}$ and $7 \mathrm{c}$ ). This result agrees well with the work by Zhang and Sun (2018), which demonstrated that the ENSO-type SST pattern experienced a significant decadal change around the late 1970s and afterward exerted an enhanced effect on circulations over East Asia in the boreal spring. The MME5 predictions could well capture the increased relationship of the tropical SST with the VORI and V850 index, with weak correlation dominating the tropics in the former period (Figs. $6 \mathrm{~b}$ and $7 \mathrm{~b}$ ) and significant ENSO-type SST (a) 1960-1976 OBS
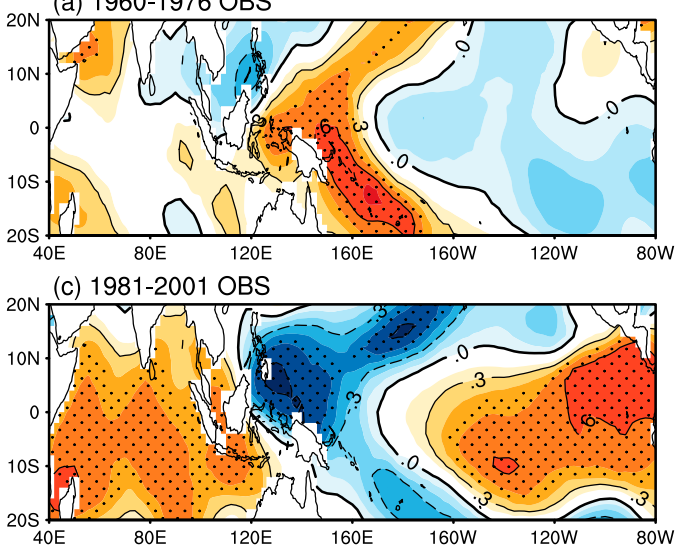

(b) 1960-1976 MME5

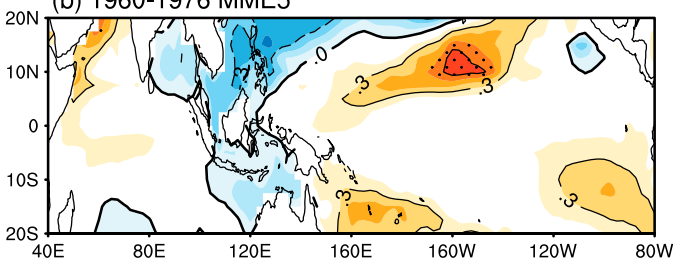

$20 \mathrm{~N}$ (d) 1981-2001 MME5

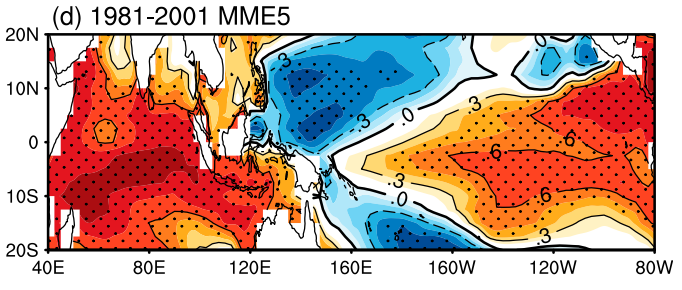

FIG. 7. As in Fig. 6, but for the V850 index. 

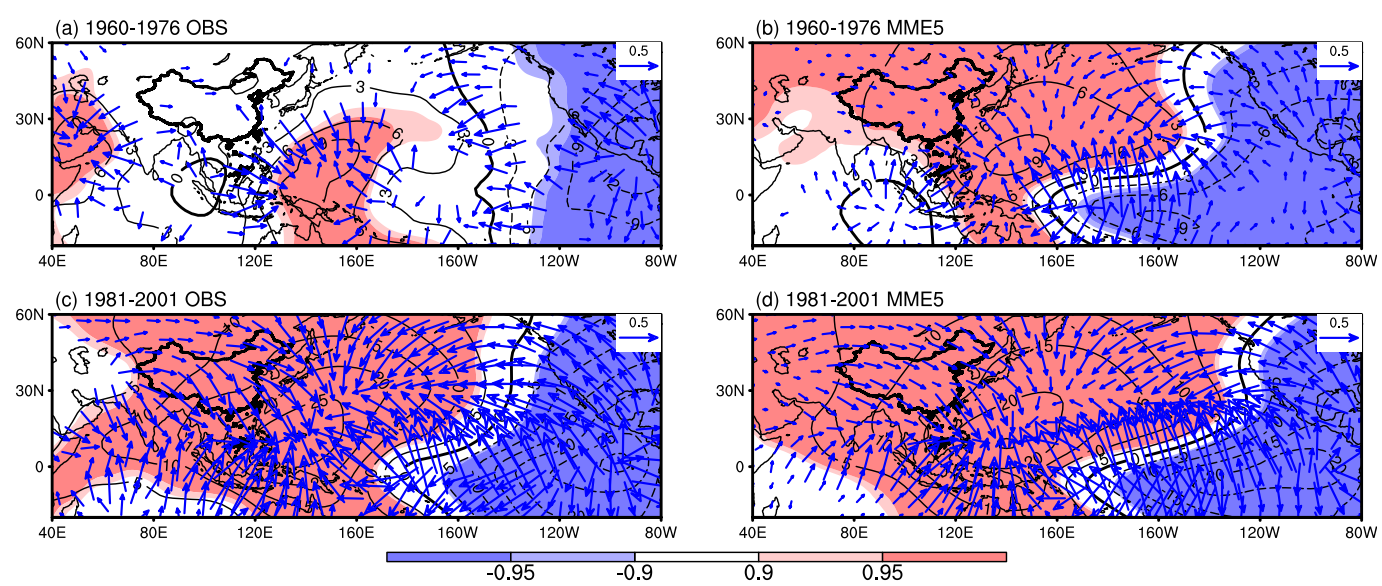

FIG. 8. Regressions of the 200-hPa divergent winds (vectors; $\mathrm{m} \mathrm{s}^{-1}$ ) and velocity potential (contours; $10^{5} \mathrm{~m}^{2} \mathrm{~s}^{-1}$ ) against the normalized tropical SST index in the (left) observations and (right) MME5 predictions during (a),(b) 1960-76 and (c),(d) 1981-2001. Light (dark) shading indicates areas that are statistically significant at the $90 \%(95 \%)$ confidence level. Only vectors that are statistically significant at the $90 \%$ confidence level are shown.

structures over the region in the latter period (Figs. 6d and $7 \mathrm{~d})$.

To be mentioned, visible differences are noted in the locations of maximum correlations of SST between observation and MME5 prediction during 1981-2001 (Figs. 6c,d as well as Figs. 7c,d). For example, there are different warming centers over the tropical Indian Ocean, which could result in different atmospheric circulations. However, our further analyses indicate that the relationship between the atmospheric circulation and tropical ENSO-like triple SST pattern over the tropical Pacific and Indian Oceans is not sensitive to the difference in the location of the SST maximum correlations between the observation and MME5 prediction (figure not shown). Therefore, a tropical SST index is defined based on the SST correlation pattern of MME5 prediction in Fig. 6d (red rectangles), described as follows:

$$
\begin{aligned}
\text { Tropical SST index }= & {\left[\mathrm{SST}_{\mathrm{A}\left(17.5^{\circ} \mathrm{S}-10^{\circ} \mathrm{N}, 40^{\circ}-110^{\circ} \mathrm{E}\right)}\right.} \\
& \left.+\mathrm{SST}_{\mathrm{B}\left(10^{\circ} \mathrm{S}-8^{\circ} \mathrm{N}, 140^{\circ}-80^{\circ} \mathrm{W}\right)}\right] \\
& \times 0.5-\mathrm{SST}_{\mathrm{C}\left(0^{\circ}-12.5^{\circ} \mathrm{N}, 140^{\circ}-160^{\circ} \mathrm{E}\right)}
\end{aligned}
$$

Figure 8 illustrates the regressed divergent winds and velocity potential at $200 \mathrm{hPa}$ against the tropical SST index in the observation and MME5 prediction. The anomalous velocity potential feature zonal dipole patterns with divergence over the eastern Pacific and convergence over the western Pacific, indicating a weakened walker circulation. The tropical SST-induced convergence (divergence) center increased from $9 \times 10^{5}(-12 \times$ $\left.10^{5}\right) \mathrm{m}^{2} \mathrm{~s}^{-1}$ over $1960-76$ to $30 \times 10^{5}\left(-30 \times 10^{5}\right) \mathrm{m}^{2} \mathrm{~s}^{-1}$ over 1981-2001 in the observation and increased from
$9 \times 10^{5}\left(-9 \times 10^{5}\right) \mathrm{m}^{2} \mathrm{~s}^{-1}$ over $1960-76$ to $25 \times 10^{5}$ $\left(-20 \times 10^{5}\right) \mathrm{m}^{2} \mathrm{~s}^{-1}$ over 1981-2001 in the MME5 prediction. The strengthened divergence and convergence after the late 1970s suggest a strengthened impact of tropical SST on the overlying atmosphere.

Figure 9 displays the tropical SST index-related 200hPa vorticity and WAFs in the observation and MME5 prediction during 1960-76 and 1981-2001. In the observation, the tropical SST-related vorticity and WAFs show obvious differences between the two periods. During the former period, the tropical SST could not excite the northward-propagated wave train over East Asia, and therefore, no large-scale significant signals are found over the region. In contrast, during the latter period, there is a meridional wave train originating from the tropical Indian Ocean to central East China, forcing a significant dipole vorticity pattern in the southnorth direction over East Asia. The MME5 prediction could reasonably capture the enhanced influence of tropical SST on East Asia circulation. During the former period, the northward-dispersed WAFs are weak and confined to South Asia. In contrast, a strong Rossby wave train originates from the tropical Indian Ocean and propagates northward to central East China, forcing a significant dipole vorticity in the meridional direction.

At the lower level, the warming SST over the eastern tropical Pacific and tropical Indian Ocean could intensify the western North Pacific anticyclone through Rossby wave response and Kelvin wave response (e.g., Wang et al. 2000; Xie et al. 2009; Chowdary et al. 2010). After the late 1970s, the tropical SST could excite a WP pattern over the western North Pacific, with atmospheric anomalies centered in the Bering 

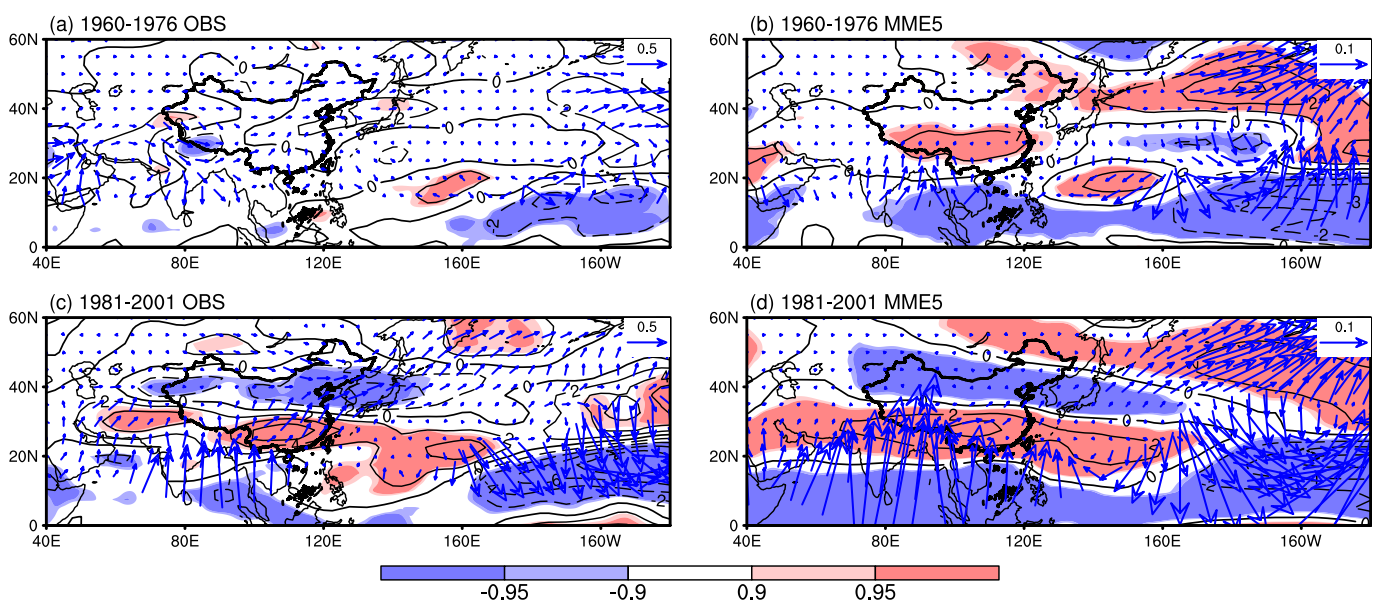

FIG. 9. Regressions of the 200-hPa vorticity (contours; $10^{-6} \mathrm{~s}^{-1}$ ) against the normalized tropical SST index and the related WAFs (vectors; $\mathrm{m}^{2} \mathrm{~s}^{-2}$ ) in the (left) observations and (right) MME5 predictions during (a),(b) 1960-76 and (c),(d) 1981-2001. Light (dark) shading indicates areas that are statistically significant at the $90 \%(95 \%)$ confidence level.

Sea region and in subtropical western North Pacific and East Asia, resembling the anomalous lower-level circulations associated with CECPI in Fig. 5 (figure not shown).

The above results indicate that the tropical SST impact on the overlying atmosphere is enhanced along with its interdecadal shift. The northward-dispersed wave energy induced by tropical SST is strengthened after the late 1970s both in the observation and in the MME5 prediction, leading to an enhanced relationship between tropical SST and CECPI-related circulations. Since tropical SST is the primary source of predictability worldwide, the significantly higher correlation between tropical SST and CECPI-related circulations would provide higher prediction skill for the CECPI-related circulations after the late 1970s.

The 21-yr running correlations of the VORI and V850 index with the tropical SST index are examined during the period of 1961-2001 to further confirm the increased relationship between tropical SST and CECSP-related circulations in the observation and MME5 prediction. As shown in Fig. 10, upward trends are found in the running correlations of the VORI and V850 index with the tropical SST index in both the observation and the model predictions. After the late 1970s, the correlations of the VORI and V850 index with the tropical SST index are significant both in the observation and in the MME5 prediction, which provides reliable predictions for the VORI and V850 index during this period. Notably, the time series of MME5 increased more steeply than that of the observation, with correlation coefficients of 0.85 for the VORI and 0.70 for the V850 index in the MME5 prediction, which are higher than those in the observation ( 0.67 for the VORI and 0.63 for the V850 index) during the period of 1981-2001. Considerably increased relationships of the VORI and V850 index with tropical SST are also found in individual models with relatively weak correlations during 1960-76 and significant high correlations during 1981-2001 (Table 4). These results suggest that model predictions could well capture the significantly enhanced relationship of the CECSP-related circulations in the upper and lower troposphere with the ENSO-type SST structure after the late 1970s, which leads to the high predictions for the VORI and V850 index during the latter period.

We also calculated the CECPI-related circulations during the former period of 1960-76 (Fig. 11). At the upper level, a meridional dipole vorticity pattern can be observed over the East Asia-northwestern Pacific region (Fig. 11a). The northward WAFs originating from the tropics are very weak; in contrast, the zonally propagated WAFs from the Mongolia-Baikal Lake region are strong. This result indicates that the CECPI and its related atmospheric circulations have a weak connection with the tropical system but a close linkage with the mid- to high-latitude system. The lower-level atmospheric circulation features a large-scale anomalous anticyclone over the midlatitude North Pacific, with two significant centers over the western and eastern North Pacific (Fig. 11c). Strong southerlies along the west flank of the anticyclone over the western North Pacific bring warm and moist air to central East China, favoring more precipitation over the region. In contrast, the anomalous winds and geopotential heights are weak over the tropics, further confirming the weak 


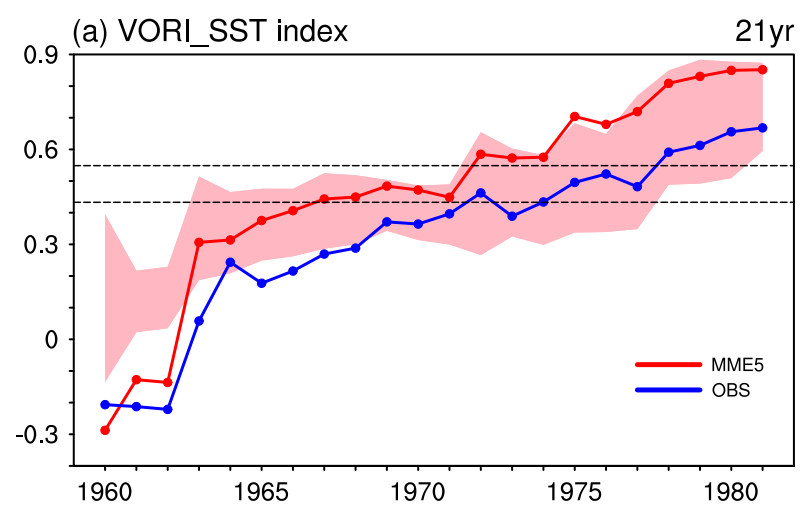

(b) V850_SST index

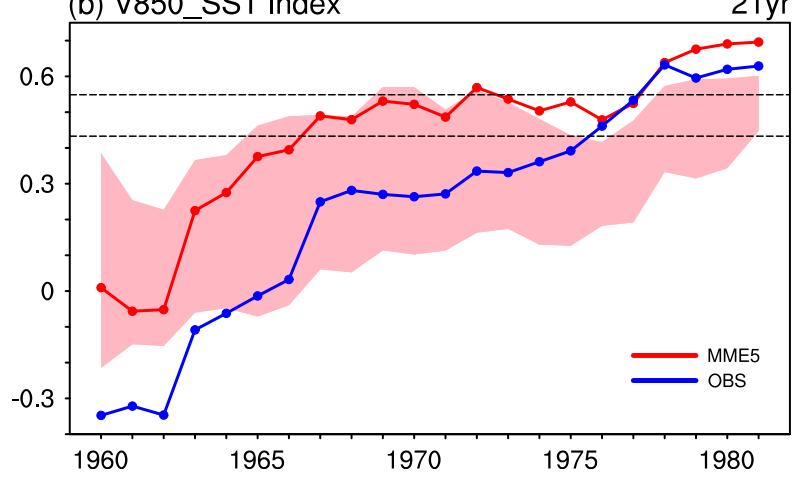

FIG. 10. The 21-yr running correlations between the tropical SST index with the (a) VORI and (b) V850 index during the period of 1960-2001 in the observation (blue line) and MME5 prediction (red line). The shading represents the range of predictions of five individual models in group 1 . The horizontal dashed lines indicate the $95 \%$ and $99 \%$ confidence levels.

relationship between CECPI and tropical SST over the period before the late 1970s.

Compared to the circulation anomalies associated with CECPI in the observation, those in the MME5 prediction are much weaker (Figs. 11b,d). The MME5 can generally predict the relationship between central East China precipitation and upper-level negative vorticity anomalies over midlatitude East China. However, the MME5 cannot capture the observed variability in the upper-level vorticity, with a correlation coefficient of -0.17 during 1960 76 between the observed and MME5 predicted vorticity indices (defined as area-averaged 200-hPa vorticity over the region of $30^{\circ}-47.5^{\circ} \mathrm{N}, 110^{\circ}-135^{\circ} \mathrm{E}$ ). Therefore, the MME5 cannot adequately predict the central East China precipitation variability during 1960-76. At the lower level, the MME5 cannot predict the observed significant anomalous anticyclone centered over northern Japan, consequently showing low predictability for central East China precipitation during 1960-76.

Additionally, the predictability of tropical SST is examined during the two periods, presented as the
TABLE 4. Correlation coefficients of the VORI and V850 index with the tropical SST index in the model predictions (five models in group 1 and MME5) and observation during 1960-76 and 19812001. Single and double asterisks indicate that the correlation coefficients are statistically significant at the $95 \%$ and $99 \%$ confidence levels, respectively.

\begin{tabular}{lrrrrr}
\hline \hline & \multicolumn{2}{c}{ VORI } & & \multicolumn{2}{c}{ V850 index } \\
\cline { 2 - 3 } \cline { 5 - 6 } \cline { 5 - 6 } & $1960-76$ & $1981-2001$ & & $1960-76$ & $1981-2001$ \\
\hline ENSEMBLES & & & & & \\
$\quad$ IFM-GEOMAR & 0.40 & $0.59^{* *}$ & & 0.40 & $0.45^{*}$ \\
$\quad$ UKMO & -0.10 & $0.71^{* *}$ & & 0.23 & $0.53^{*}$ \\
DEMETER & & & & & \\
$\quad$ CNRM & 0.29 & $0.87^{* *}$ & & 0.10 & $0.46^{*}$ \\
$\quad$ UKMO & -0.10 & $0.63^{* *}$ & & -0.20 & $0.47^{*}$ \\
$\quad$ ECMWF & 0.02 & $0.80^{* *}$ & & 0.16 & $0.60^{* *}$ \\
MME5 & -0.24 & $0.85^{* *}$ & & -0.04 & $0.70^{* *}$ \\
OBS & -0.22 & $0.67^{* *}$ & & -0.36 & $0.63^{* *}$ \\
\hline
\end{tabular}

TCC between the observation and MME5 prediction (Fig. 12). The results suggest that the tropical SST is highly predictable during both periods, with large-scale significant signals over the tropical region between $20^{\circ} \mathrm{S}$ and $20^{\circ} \mathrm{N}$ (Figs. 12a,b). It should be noted that before the late 1970s, relatively low skills are found over some regions of the southeastern tropical Indian Ocean and western and eastern tropical Pacific, with correlations not exceeding the $95 \%$ confidence level. In contrast, after the late 1970s, significant correlations are increased for both area and value, indicating a higher prediction skill of tropical SST during this period; these results agree well with previous studies (e.g., Tang et al. 2008; C. Li et al. 2016). The improvement in tropical SST predictability is better illustrated in the differences in TCC between the two periods (Fig. 12c). Increased skill is found to dominate the tropics, especially the regions over the southeastern tropical Indian Ocean, the warm pool, and the eastern tropical Pacific. Specifically, the increased predictability of the eastern tropical Pacific SST should be related to the increased predictability of ENSO, which is significant for seasonal prediction of global climate variability.

In general, a significant increase in the relationships of the VORI and V850 index with tropical SST is identified in the observation, and the MME5 prediction exhibits the capability for reproducing the changes. After the late 1970s, the significant teleconnection between VORI (V850 index) and tropical SST leads to a highly predictable VORI (V850 index). Additionally, the higher predictability of tropical SST after the late 1970s contributes to the better prediction skill of the VORI and V850 index. Therefore, the upper-level dipole vorticity pattern and lower-level meridional winds are predicted with high fidelity after the late 1970s, which further 

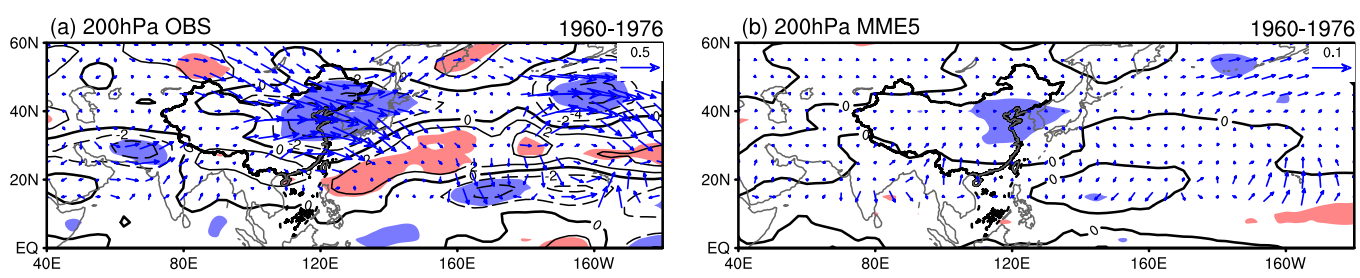

(c) $850 \mathrm{hPa}$ OBS

1960-1976
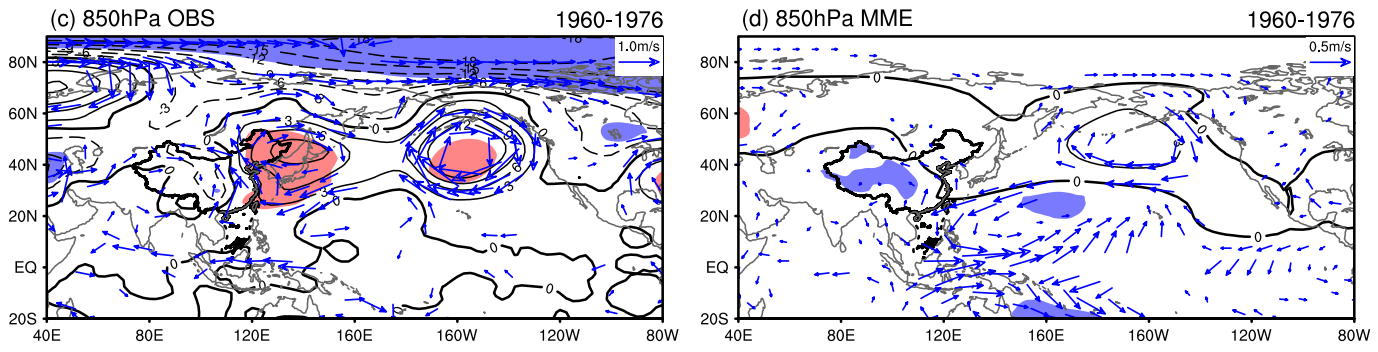

$-0.95$

0.95

FIG. 11. Regressions of the 200-hPa vorticity (contours; $10^{-6} \mathrm{~s}^{-1}$ ) against the normalized CECPI during 1960-76 and the related WAFs (vectors; $\mathrm{m}^{2} \mathrm{~s}^{-2}$ ) in the (a) observation and (b) MME5 prediction. (c),(d) As in (a) and (b), but for the 850-hPa geopotential heights (contours; gpm) and winds (vectors; $\mathrm{m} \mathrm{s}^{-1}$ ). Shading indicates areas that are statistically significant at the $95 \%$ confidence level. Only wind vectors that are statistically significant at the $90 \%$ confidence level are shown.

favors high predictability of central East China spring precipitation.

\section{Discussion and conclusions}

\section{a. Discussion}

The above analyses are applied to the five models of group 1 , which have a significantly high prediction skill of CECSP after the late 1970s. It should be mentioned that the three models of group 2 are excluded from the MME5 because of their poor prediction skill of CECSP after the late 1970s. This section explores the possible causes for the poor capability of the three models of group 2 in simulating the CECSP.

Figure 13a depicts the CECPI-related anomalous vorticity and WAFs at $200 \mathrm{hPa}$ during 1981-2001, calculated using the MME of the three models in group 2 (MME3). The anomalous vorticity displays a different structure from that in the observation. The observed dipole vorticity pattern in the meridional direction is replaced by a negative vorticity center over midlatitude East Asia in MME3 (centered over the Japan Sea). Almost no meridional wave train originates from the tropics, whereas the zonal wave train from the midlatitude Eurasian continent is strong. Large-scale significant positive anomalies are found over the midlatitude Eurasian continent, which might be caused by land forcing over the region. Figure $13 \mathrm{~b}$ exhibits the CECPI-related 850-hPa geopotential heights and winds in MME3 during 1981-2001. Corresponding to above- normal CECSP, the anomalous geopotential heights feature a significant zonal dipole pattern over midlatitude East Asia, with strong southerlies over central East China that favor precipitation. However, this zonal dipole structure over East Asia is different from the observed meridional dipole structure over the western North Pacific and East Asia. These results indicate that the MME3 is deficient in simulating the relationship between CECSP and East Asian atmospheric circulations obtained from the observation.

Further, the forecast skill of the CECPI-related upper-level circulation anomalies in the three models of group 2 is examined using a vorticity index (defined as the $200-\mathrm{hPa}$ vorticity averaged over the region of $30^{\circ}-$ $47.5^{\circ} \mathrm{N}, 115^{\circ}-140^{\circ} \mathrm{E}$; red rectangle in Fig. 13a). The predictability of CECPI-related lower-level circulations in MME3 is evaluated using a new V850 index (defined as the $850-\mathrm{hPa}$ meridional wind averaged over the region of $25^{\circ}-45^{\circ} \mathrm{N}, 105^{\circ}-120^{\circ} \mathrm{E}$; red rectangle region in Fig. 13b). The CECPI is significantly correlated with the vorticity index as well as the V850 index in the three models of group 2 and in MME3 during both periods (Table 5). Figure 14 displays the 21-yr running correlations of the vorticity index and the V850 index between observation and model predictions. The prediction correlations are weak or negative during the entire period for all three models and their MME. The corresponding correlation coefficients are shown in Table 6. All correlation coefficients are low or negative. Therefore, the low forecast skill of the CECSP-related circulation favors low 
(a) 1960-1976 TCC
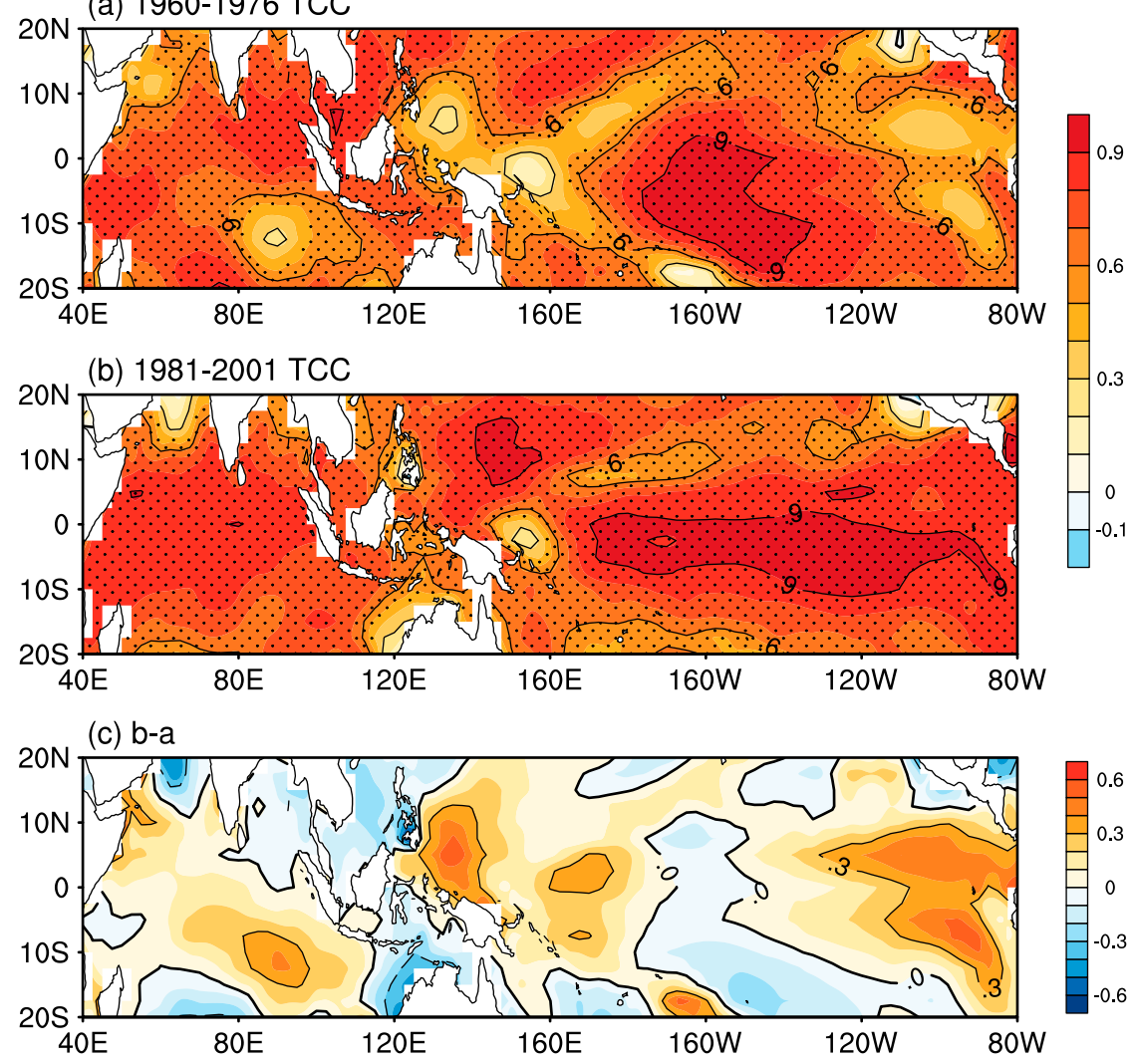

FIG. 12. As in Fig. 2, but for tropical SST. Areas that are statistically significant at the $95 \%$ confidence level are stippled.

prediction skill for precipitation over central East China in these three models.

The relationship of the tropical SST with the vorticity index and V850 index is also examined in MME3 for the periods of 1960-76 and 1981-2001. As shown in Fig. 15, the MME3 could not reproduce the observed enhanced relationship between tropical SST and East Asian atmospheric circulation after the late 1970s. There are few significant areas over the tropics after the late 1970s (Figs. 15c,d), indicating weak relationships between tropical SST and the CECPI-related circulations during the period in MME3. Therefore, it could be concluded that the three models do not have the capability of capturing the enhanced relationship between the CECSP-related anomalous circulations and tropical SST, which leads to poor predictability of the circulation anomalies associated with CECSP after the late 1970s. Subsequently, the low prediction skill of the CECSP-related circulations favors low prediction skill of East China spring precipitation.

\section{b. Conclusions}

In the present study, DEMETER and ENSMBLES February-start seasonal predictions are used to examine the prediction skill for East China spring precipitation. There are eight global ocean-atmosphere coupled models covering the common period of 1960-2001. The running correlation and the TCC methods are employed to measure the evolution and spatial distribution of the prediction skill.

The results revealed that the seasonal prediction skill for central East China spring precipitation experienced a significant increase after the late 1970s. In the former period, weak prediction correlations of CECPI are noted in all eight models. In the latter period, five out of the eight models exhibit considerably increased predictability, with significantly higher prediction correlations during this period, whereas the correlations of the other three models are insignificant. Thus, the five models with high predictability during the latter period (group 1) and the three models with poor predictability (group 2) are investigated to detect the predictability source. The correlation of CECPI between the MME5 prediction and observation increased from -0.30 during 1960-76 to 0.77 during 1981-2001, significant at the $99 \%$ confidence level in the latter period. The significant change in predictability is also concluded in the 


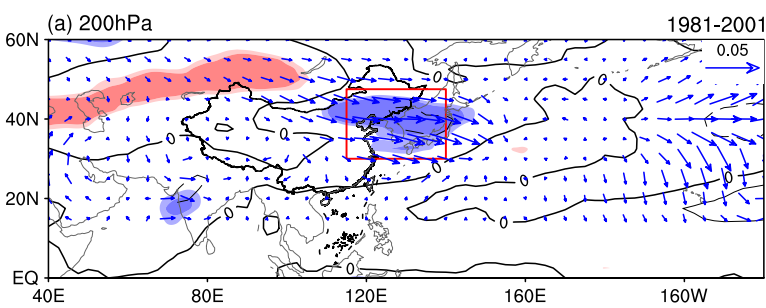

(b) $850 \mathrm{hPa}$

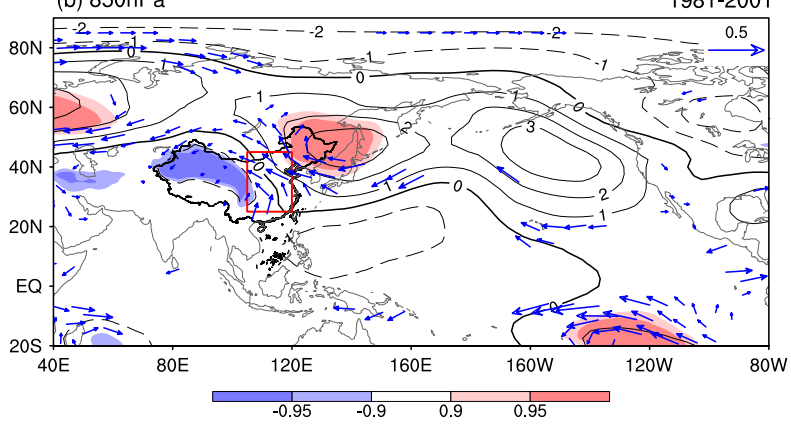

FIG. 13. (a) Regression of the 200-hPa vorticity (contours; $10^{-6} \mathrm{~s}^{-1}$ ) on the normalized CECPI and the related WAFs (vectors; $\mathrm{m}^{2} \mathrm{~s}^{-2}$ ) during 1981-2001 in the MME3 prediction (MME of the three models in group 2, with low skills of CECSP during 19812001). (b) Regressions of the 850-hPa geopotential heights (contours; gpm) and winds (vectors; $\mathrm{m} \mathrm{s}^{-1}$ ) against the normalized CECPI during 1981-2001 in the MME3 prediction. Only wind vectors that are statistically significant at the $90 \%$ confidence level are shown. Light (dark) shading indicates areas that are statistically significant at the $90 \%$ (95\%) confidence level. The red rectangles indicate the domains used to define the (a) vorticity index and (b) V850 index.

TCC results, with considerable improvement over central East China.

The increased prediction skill of CECSP is associated with the increased predictability of CECSP-related atmospheric circulations. An upper-level dipole vorticity pattern is observed related to the CECSP, which is reasonably reproduced by the MME5 prediction as well as the five individual models. The correlation of VORI

TABLE 5. Correlation coefficients of the vorticity index and V850 index with the CECPI in the predictions for the three models in group 2 and their MME during 1960-76 and 1981-2001. Single, double, and triple asterisks indicate that the correlation coefficients are statistically significant at the $90 \%, 95 \%$, and $99 \%$ confidence levels, respectively.

\begin{tabular}{llllll}
\hline \hline & \multicolumn{2}{c}{ Vorticity index } & & \multicolumn{2}{c}{ V850 index } \\
\cline { 2 - 3 } \cline { 5 - 6 } & $1960-76$ & $1981-2001$ & & $1960-76$ & $1981-2001$ \\
\hline ENSEMBLES & & & & & \\
ECMWF & $-0.71 * * *$ & $-0.56 * * *$ & & $0.75^{* * *}$ & $0.54 * *$ \\
MF & $-0.91 * * *$ & $-0.86^{* * * *}$ & & $0.92^{* * *}$ & $0.89 * * *$ \\
CMCC-INGV & $-0.65 * * *$ & $-0.61 * * *$ & & $0.75^{* * *}$ & $0.63 * * *$ \\
MME3 & $-0.77^{* * *}$ & $-0.71^{* * *}$ & & $0.88^{* * *}$ & $0.78^{* * *}$ \\
\hline
\end{tabular}

(a) vorticity index $21 \mathrm{yr}$

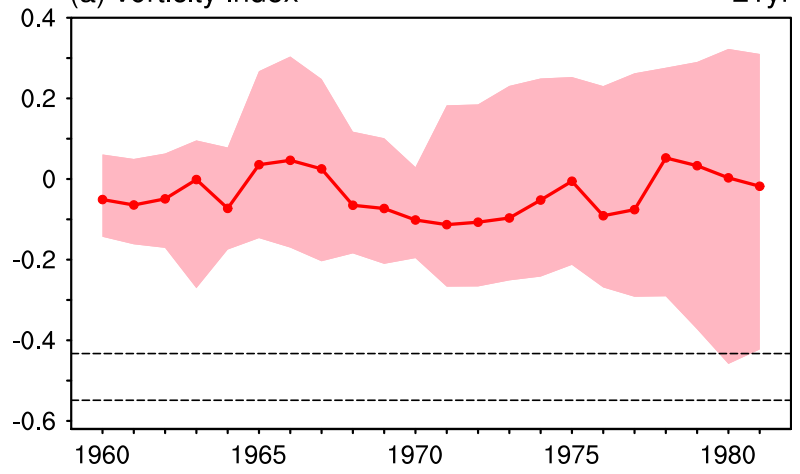

(b) V850 index

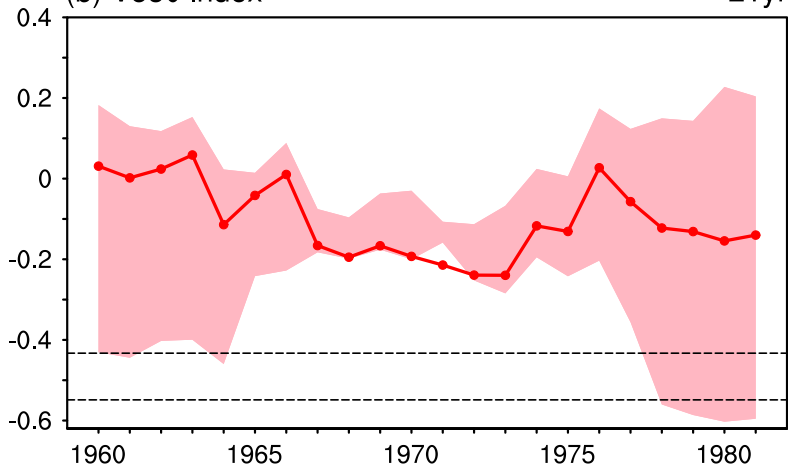

FIG. 14. The 21-yr running correlations of the (a) vorticity index and (b) V850 index between the observation and model predictions in group 2 during the period of 1960-2001. The line (shading) represents the MME3 prediction (range of predictions of three individual models). The dashed lines indicate the $95 \%$ and $99 \%$ confidence levels.

between the MME5 prediction and observation increased to 0.63 during $1981-2001$ but is only 0.21 during 1960-76. At the lower level, the west Pacific (WP) pattern is observed to significantly impact the CECSP, and the southerly along the west flank of the anticyclone over the western North Pacific and East Asia (southern

TABLE 6. Correlation coefficients between the observed and predicted vorticity index and V850 index during 1960-76 and 19812001 for the three models in group 2 and their MME. Single, double, and triple asterisks indicate that the correlation coefficients are statistically significant at the $90 \%, 95 \%$, and $99 \%$ confidence levels, respectively.

\begin{tabular}{lccccc}
\hline \hline & \multicolumn{2}{c}{ Vorticity index } & & \multicolumn{2}{c}{ V850 index } \\
\cline { 2 - 3 } \cline { 5 - 6 } & $1960-76$ & $1981-2001$ & & $1960-76$ & $1981-2001$ \\
\hline ENSEMBLES & & & & & \\
ECMWF & -0.27 & 0.31 & & $-0.41^{*}$ & 0.20 \\
MF & -0.10 & 0.19 & & 0.08 & 0.06 \\
CMCC-INGV & 0.09 & $-0.42^{*}$ & & 0.13 & $-0.60^{* * *}$ \\
MME3 & -0.11 & -0.02 & & -0.02 & -0.14 \\
\hline
\end{tabular}



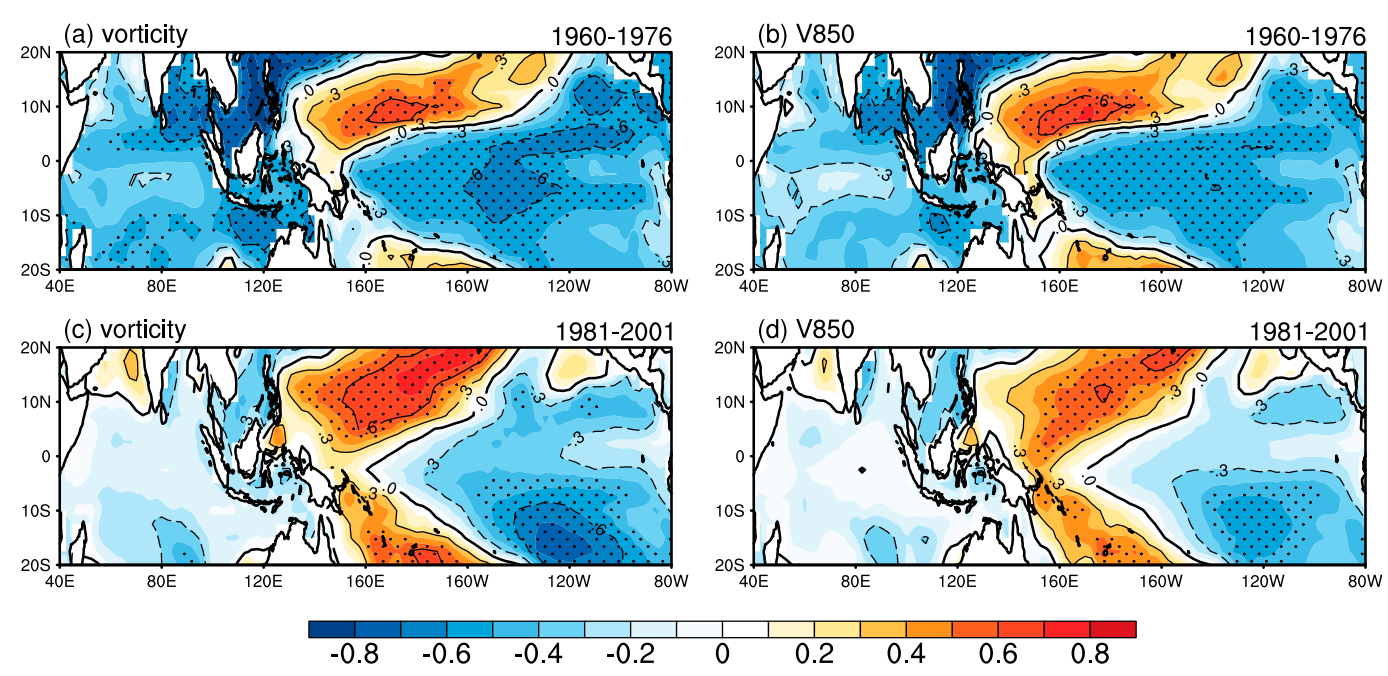

FIG. 15. Correlations of tropical SST associated with the (a),(c) vorticity index (multiplied by -1 ) and (b),(d) V850 index in the MME3 prediction during (top) 1960-76 and (bottom) 1981-2001. Areas that are statistically significant at the $95 \%$ confidence level are stippled.

part of the WP pattern) is important for precipitation over central East China. The MME5 prediction could generally capture the meridional dipole pattern over the western North Pacific and the southerly over central East China. The correlation of the V850 index between the MME5 prediction and observation increased significantly from 0.04 (1960-76) to 0.67 (1981-2001). The well-predicted VORI and V850 index after the late 1970s is related to the high predictability of CECSP during this period.

The tropical SST is known to be the main source of seasonal predictability in the extratropics via SST-induced teleconnection patterns (e.g., Lee et al. 2013; Jia et al. 2014; C. Li et al. 2016). Some previous studies have shown that the tropical SST experienced an interdecadal change toward a warmer state after the late 1970s (Nitta and Yamada 1989; Wallace et al. 1998; Lau and Weng 1999; Terray and Dominiak 2005). After the regime shift around the late 1970s, the response of tropical Indian SST to El Niño decay changed and seems to have some impact on East Asian rainfall (e.g., Xie et al. 2010; Huang et al. 2010; Chowdary et al. 2012). Further, the change in variance of ENSO itself after the decadal regime shift helped to enhance the relationship between tropical SST and East Asian rainfall (e.g., Wang et al. 2008; Hu et al. 2014; Zhang and Sun 2018). A pronounced enhancement in the relationship between the tropical SST and the VORI and V850 index is noted both in the observation and in the MME5 prediction. After the late 1970s, a typical ENSOtype SST pattern is significantly correlated with the VORI and V850 index, which leads to a highly predictable VORI and V850 index. Additionally, after the late 1970s, the higher prediction skill of the tropical SST contributes to the higher prediction skill of the VORI and V850 index. The reasonably predicted VORI and V850 index further favor high predictability of central East China spring precipitation.

Furthermore, the causes for the low prediction skill of the three models (group 2) in CECSP are discussed. The CECPI-related anomalous vorticity at $200 \mathrm{hPa}$ is characterized by a significant negative center over East Asia in the MME3, which is different from the meridional dipole pattern in the observation. The CECPI-related 850-hPa geopotential heights feature a zonal dipole pattern over midlatitude East Asia in the MME3, which is different from the observed WP pattern. Low prediction skill of anomalous vorticity and V850 indices associated with the CECPI are noted after the late 1970s in all three models and the MME3.

Further investigations reveal that the MME3 exhibits a weak relationship between CECPI-related vorticity anomalies and southerly winds with tropical SST after the late 1970s. Compared to the results of the MME5, it could be concluded that the low skill of CECSP in the MME3 is associated with the low skill of CECSP-related vorticity anomalies and southerly winds, which is further attributed to the models' deficiency in reproducing the relationship between the vorticity anomalies and southerly winds with tropical SST. In general, the significant increase in the prediction skill of CECSP is associated with the models' capability to reproduce the change in the relationship between CECSP-related circulation and tropical SST.

In conclusion, the increased contribution of the tropical SST to the variability in East Asian atmospheric circulation in spring provides a prediction source for East Asian 
spring climate prediction in the last four decades. Capturing such a relationship by the models can improve the dynamical predictability of the East Asian spring climate. The results of this study are therefore valuable for operational forecasts of East China spring precipitation.

Acknowledgments. This work was jointly supported by the National Key Research and Development Program of China (2017YFC1502304) and National Natural Science Foundation of China (41825010 and 41421004).

\section{REFERENCES}

Annamalai, H., S. P. Xie, J. P. McCreary, and R. Murtugudde, 2005: Impact of Indian Ocean sea surface temperature on developing El Niño. J. Climate, 18, 302-319, https://doi.org/ 10.1175/JCLI-3268.1.

Barnston, A. G., and R. E. Livezey, 1987: Classification, seasonality and persistence of low-frequency atmospheric circulation patterns. Mon. Wea. Rev., 115, 1083-1126, https://doi.org/ 10.1175/1520-0493(1987)115<1083:CSAPOL > 2.0.CO;2.

Chowdary, J. S., S.-P. Xie, J.-Y. Lee, Y. Kosaka, and B. Wang, 2010: Predictability of summer northwest Pacific climate in 11 coupled model hindcasts: Local and remote forcing. J. Geophys. Res., 115, D22121, https://doi.org/10.1029/2010JD014595.

_ - J.-J. Luo, J. Hafner, S. Behera, Y. Masumoto, and T. Yamagata, 2011: Predictability of northwest Pacific climate during summer and the role of the tropical Indian Ocean. Climate Dyn., 36, 607-621, https://doi.org/10.1007/s00382-0090686-5.

,,-- H. Tokinaga, Y. M. Okumura, H. Kubota, N. Johnson, and X.-T. Zheng, 2012: Interdecadal variations in ENSO teleconnection to the Indo-western Pacific for 1870-2007. J. Climate, 25, 1722-1744, https://doi.org/10.1175/JCLI-D-1100070.1 .

Doblas-Reyes, F. J., M. Déqué, and J.-P. Piedelievre, 2000: Multimodel spread and probabilistic seasonal forecasts in PROVOST. Quart. J. Roy. Meteor. Soc., 126, 2069-2087, https://doi.org/10.1002/qj.49712656705.

- R. Hagedorn, and T. N. Palmer, 2005: The rationale behind the success of multi-model ensembles in seasonal forecasting-II Calibration and combination. Tellus, 57A, 234-252, https:// doi.org/10.1111/j.1600-0870.2005.00104.x.

_ sonal and annual dynamical ensemble forecast. Quart. J. Roy. Meteor. Soc., 135, 1538-1559, https://doi.org/10.1002/qj.464.

Feng, J., and J. Li, 2011: Influence of El Niño Modoki on spring rainfall over south China. J. Geophys. Res., 116, D13102, https://doi.org/10.1029/2010JD015160.

Gao, R., 2009: Local storm rainfall caused flood in the south and Huanghuai areas drought development in Heilongjiang (in Chinese). Meteor. Mon., 35, 124-125.

Graham, N. E., 1995: Simulation of recent global temperature trends. Science, 267, 666-671, https://doi.org/10.1126/science.267.5198.666.

Hagedorn, R., F. J. Doblas-Reyes, and T. N. Palmer, 2005: The rationale behind the success of multi-model ensembles in seasonal forecasting-I. Basic concept. Tellus, 57A, 219-233, https://doi.org/10.1111/j.1600-0870.2005.00103.x.

Han, J., H. Wang, and D. Jiang, 2006: Interannual variation of spring precipitation and circulation in southern China as simulated by a coupled model (in Chinese). Climatic Environ. Res., 11, 194-202.

Hu, K., G. Huang, X.-T. Zheng, S.-P. Xie, X. Qu, Y. Du, and L. Liu, 2014: Interdecadal variations in ENSO influences on Northwest Pacific-East Asian early summertime climate simulated in CMIP5 models. J. Climate, 27, 5982-5998, https:// doi.org/10.1175/JCLI-D-13-00268.1.

Huang, B., and Coauthors, 2015: Extended Reconstructed Sea Surface Temperature version 4 (ERSST.v4). Part I: Upgrades and intercomparison. J. Climate, 28, 911-930, https://doi.org/ 10.1175/JCLI-D-14-00006.1.

Huang, G., K. Hu, and S.-P. Xie, 2010: Strengthening of tropical Indian Ocean teleconnection to the northwest Pacific since the mid-1970s: An atmospheric GCM study. J. Climate, 23, 52945304, https://doi.org/10.1175/2010JCLI3577.1.

Jia, X., J.-Y. Lee, H. Lin, H. Hendon, and J.-K. Ha, 2014: Interdecadal change in the Northern Hemisphere seasonal climate prediction skill: Part II. Predictability and prediction skill. Climate Dyn., 43, 1611-1630, https://doi.org/10.1007/s00382014-2084-x.

Jin, D., Z. Guan, and W. Tang, 2013: The extreme drought event during winter-spring of 2011 in East China: Combined influences of teleconnection in midhigh latitudes and thermal forcing in Maritime Continent region. J. Climate, 26, 8210 8222, https://doi.org/10.1175/JCLI-D-12-00652.1.

Kalnay, E., and Coauthors, 1996: The NCEP-NCAR 40-Year Reanalysis Project. Bull. Amer. Meteor. Soc., 77, 437-471, https:// doi.org/10.1175/1520-0477(1996)077<0437:TNYRP>2.0.CO;2.

Kosaka, Y., S. P. Xie, N.-C. Lau, and G. A. Vecchi, 2013: Origin of seasonal predictability for summer climate over the northwestern Pacific. Proc. Natl. Acad. Sci. USA, 110, 7574-7579, https://doi.org/10.1073/pnas.1215582110.

Lau, K.-M., and H. Y. Weng, 1999: Interannual, decadalinterdecadal, and global warming signals in sea surface temperature during 1955-97. J. Climate, 12, 1257-1267, https://doi.org/ 10.1175/1520-0442(1999)012<1257:IDIAGW>2.0.CO;2.

Lee, J.-Y., S.-S. Lee, B. Wang, J.-K. Ha, and J.-G. Jhun, 2013: Seasonal prediction and predictability of the Asian winter temperature variability. Climate Dyn., 41, 573-587, https:// doi.org/10.1007/s00382-012-1588-5.

Li, C., R. Lu, and B. Dong, 2016: Interdecadal changes on the seasonal prediction of the western North Pacific summer climate around the late 1970s and early 1990s. Climate Dyn., 46, 2435-2448, https://doi.org/10.1007/s00382-015-2711-1.

Li, X., J. Li, and Y. Li, 2015: Recent winter precipitation increase in the middle-lower Yangtze River valley since the late 1970s: A response to warming in the tropical Indian Ocean. J. Climate, 28, 3857-3879, https://doi.org/10.1175/JCLI-D-14-00701.1.

Li, Z. N., S. Yang, B. He, and C. D. Hu, 2016: Intensified springtime deep convection over the South China Sea and the Philippine Sea dries southern China. Sci. Rep., 6, 30470, https://doi.org/ 10.1038/srep30470.

Lu, R. Y., 2001: Atmospheric circulation anomaly associated with the spring rainfall anomaly in North China (in Chinese). Climatic Environ. Res., 6, 400-408.

Nitta, T., 1987: Convective activities in the tropical western Pacific and their impact on the Northern Hemisphere summer circulation. J. Meteor. Soc. Japan, 65, 373-390, https://doi.org/ 10.2151/jmsj1965.65.3_373. 1989: Global features of the Pacific-Japan oscillation. Meteor. Atmos. Phys., 41, 5-12, https://doi.org/10.1007/BF01032585. , and S. Yamada, 1989: Recent warming of tropical sea surface temperature and its relationship to the Northern Hemisphere 
circulation. J. Meteor. Soc. Japan, 67, 375-383, https://doi.org/ 10.2151/jmsj1965.67.3_375.

— its association with $500 \mathrm{hPa}$ height and tropical convection. J. Meteor. Soc. Japan, 74, 425-445, https://doi.org/10.2151/ jmsj1965.74.4_425.

Palmer, T. N., and Coauthors, 2004: Development of a European multimodel ensemble system for seasonal-to-interannual prediction (DEMETER). Bull. Amer. Meteor. Soc., 85, 853872, https://doi.org/10.1175/BAMS-85-6-853.

Pradhan, M., R. K. Yadav, A. Ramu Dandi, A. Srivastava, M. K. Phani, and S. A. Rao, 2017: Shift in monsoon-SST teleconnections in the tropical Indian Ocean and ENSEMBLES climate models' fidelity in its simulation. Int. J. Climatol., 37, 2280-2294, https://doi.org/10.1002/joc.4841.

Rajeevan, M., C. K. Unnikrishnan, and B. Preethi, 2012: Evaluation of the ENSEMBLES multi-model seasonal forecasts of Indian summer monsoon variability. Climate Dyn., 38, 22572274, https://doi.org/10.1007/s00382-011-1061-x.

Rong, Y., L. Duan, and M. Xu, 2008: Analysis on climatic diagnosis of persistent drought in North China during the period from 1997 to 2002 (in Chinese). Arid Zone Res., 25, 842-850.

Shao, T., and Y. Zhang, 2012: Influence of winter North Atlantic Oscillation on spring precipitation in China (in Chinese). Plateau Meteor., 31, 1225-1233.

Srinivas, G., J. S. Chowdary, Y. Kosaka, C. Gnanaseelan, A. Parekh, and K. V. S. R. Prasad, 2018: Influence of the Pacific-Japan pattern on Indian summer monsoon rainfall. J. Climate, 31, 3943-3958, https://doi.org/10.1175/JCLI-D-17-0408.1.

Sun, C., and S. Yang, 2012: Persistent severe drought in southern China during winter-spring 2011: Large-scale circulation patterns and possible impacting factors. J. Geophys. Res., 117, D10112, https://doi.org/10.1029/2012JD017500.

Tang, Y., Z. Deng, X. Zhou, Y. Cheng, and D. Chen, 2008: Interdecadal variation of ENSO predictability in multiple models. J. Climate, 21, 4811-4833, https://doi.org/10.1175/2008JCLI2193.1.

Terray, P., and S. Dominiak, 2005: Indian Ocean sea surface temperature and El Niño-Southern Oscillation: A new perspective. J. Climate, 18, 1351-1368, https://doi.org/10.1175/ JCLI3338.1.

Trenberth, K. E., 1990: Recent observed interdecadal climate changes in the Northern Hemisphere. Bull. Amer. Meteor. Soc., 71, 988-993, https://doi.org/10.1175/1520-0477(1990) 071<0988:ROICCI $>2.0$.CO;2.

Wakabayashi, S., and R. Kawamura, 2004: Extraction of major teleconnection patterns possibly associated with the anomalous summer climate in Japan. J. Meteor. Soc. Japan, 82, 15771588, https://doi.org/10.2151/jmsj.82.1577.

Wallace, J. M., and D. S. Gutzler, 1981: Teleconnections in the geopotential height field during the Northern Hemisphere winter. Mon. Wea. Rev., 109, 784-812, https://doi.org/10.1175/ 1520-0493(1981)109<0784:TITGHF>2.0.CO;2.

—, E. M. Rasmusson, T. P. Mitchell, V. E. Kousky, E. S. Sarachik, and H. von Storch, 1998: On the structure and evolution of ENSO-related climate variability in the tropical Pacific: Lessons from TOGA. J. Geophys. Res., 103, 1424114 259, https://doi.org/10.1029/97JC02905.

Wang, B., R. Wu, and X. Fu, 2000: Pacific-East Asian teleconnection: How does ENSO affect East Asian climate? J. Climate, 13, 1517-1536, https://doi.org/10.1175/1520-0442(2000) 013<1517:PEATHD $>2.0$. CO;2.
_ J. Jang, T. Zhou, and B. Wang, 2008: Interdecadal changes in the major modes of Asian-Australian monsoon variability: Strengthening relationship with ENSO since the late 1970s. J. Climate, 21, 1771-1789, https://doi.org/10.1175/2007JCLI1981.1. , and Coauthors, 2009: Advance and prospectus of seasonal prediction: Assessment of the APCC/CliPAS 14-model ensemble retrospective seasonal prediction (1980-2004). Climate Dyn., 33, 93-117, https://doi.org/10.1007/s00382-008-0460-0.

Wang, H., F. Xue, and G. Zhou, 2002: The spring monsoon in south China and its relationship to large-scale circulation features. Adv. Atmos. Sci., 19, 651-664, https://doi.org/10.1007/s00376002-0005-0.

Weisheimer, A., and Coauthors, 2009: ENSEMBLES: A new multi-model ensemble for seasonal-to-annual predictionsSkill and progress beyond DEMETER in forecasting tropical Pacific SSTs. Geophys. Res. Lett., 36, L21711, https://doi.org/ 10.1029/2009GL040896.

Wu, R., and B. Wang, 2002: A contrast of the East Asian summer monsoon-ENSO relationship between 1962-77 and 1978-93 J. Climate, 15, 3266-3279, https://doi.org/10.1175/1520-0442(2002) 015<3266:ACOTEA > 2.0.CO;2.

$\mathrm{Wu}, \mathrm{X}$., and J. Mao, 2018: Spatial and interannual variations of spring rainfall over eastern China in association with PDOENSO events. Theor. Appl. Climatol., 134, 935-953, https:// doi.org/10.1007/s00704-017-2323-2.

Xie, S.-P., K. Hu, J. Hafner, H. Tokinaga, Y. Du, G. Huang, and T. Sampe, 2009: Indian Ocean capacitor effect on Indo-western Pacific climate during the summer following El Niño. J. Climate, 22, 730-747, https://doi.org/10.1175/2008JCLI2544.1.

_ , Y. Du, G. Huang, X.-T. Zheng, H. Tokinaga, K. Hu, and Q. Liu, 2010: Decadal shift in El Niño influences on Indo-western Pacific and East Asian climate in the 1970s. J. Climate, 23, 3352-3368, https://doi.org/10.1175/2010JCLI3429.1.

Xin, X., R. Yu, T. Zhou, and B. Wang, 2006: Drought in late spring of south China in recent decades. J. Climate, 19, 3197-3206, https://doi.org/10.1175/JCLI3794.1.

Zhang, J., T. Zhou, R. Yu, and X. Xin, 2009: Atmospheric water vapor transport and corresponding typical anomalous spring rainfall patterns in China (in Chinese). Chin. J. Atmos. Sci., 33, 121-134.

Zhang, M., and J. Sun, 2018: Enhancement of the spring East China precipitation response to tropical sea surface temperature variability. Climate Dyn., 51, 3009-3021, https://doi.org/10.1007/ s00382-017-4061-7.

Zheng, F., J. Li, L. Wang, F. Xie, and X. Li, 2015: Cross-seasonal influence of the December-February Southern Hemisphere annular mode on March-May meridional circulation and precipitation. J. Climate, 28, 6859-6881, https://doi.org/10.1175/ JCLI-D-14-00515.1.

Zhou, B., 2013: Weakening of winter North Atlantic Oscillation signal in spring precipitation over southern China. Atmos. Ocean. Sci. Lett., 6, 248-252, https://doi.org/10.3878/j.issn.16742834.13.0010.

_ and P. Zhao, 2010: Influence of the Asian-Pacific oscillation on spring precipitation over central eastern China. Adv. At mos. Sci., 27, 575-582, https://doi.org/10.1007/s00376-0099058-7.

Zuo, Z., and R. Zhang, 2012: The anomalies of spring rainfall in China and its relation with tropical Pacific SST and Eurasian snow (in Chinese). Chin. J. Atmos. Sci., 36, 185-194. 